\title{
Professional deontology and medical practice in prisons
}

\author{
J García-Guerrero, EJ Vera-Remartínez
}

Medical Services of the Prison of Castellon I

\begin{abstract}
:
Objective: To study the knowledge on professional deontology amongst doctors in prisons.

Materials and Method: Descriptive, transversal and multi-centre study. Labour, collegiate, social, demographic and deontological variables were collected. A descriptive analysis of the variables was performed. A bivariate analysis was made by binary logistic regression models, attending to the odds ratio, and assuming a $95 \%$ confidence interval. Data was processed by SPSS v.20 software.

Results: 118 doctors replied. 68 men (57.6\%), with an average age of 51 years (50-53). 100 know about the Deontology Committee $(84.7 \%)$, but just $77(65.3 \%)$ know its functions properly. 42 (35.6\%) know about the existence of the Deontological Code, and $37(31.3 \%)$ have read and apply it. Those who made a correct definition of deontology do find more deontological issues in their daily work [23(46.9\%) vs. 18(26.1\%); OR: 2.506; IC95\%: 1.153-5.451; $\mathrm{p}=0.020$ ] and would denounce a colleague more often to the Medical Association [40(81.6\%) vs. 42 (60.9\%); OR: 2.857; IC95\%: 1.197-6.819; p=0.018]. Older ones know more about the deontology commissions' functions [54(73\%) vs. 23(52.3\%); OR: 2.465; IC95\%: 1.127-5.394; p=0.024] and have already denounced situations to the Medical Association [27(36.5\% vs. 5(11.4\%); OR: 4.481; IC95\%: 1.577-12.733; $\mathrm{p}=0.005]$, but think that a different Care Ethics Committee is unnecessary [57(77\%) vs. 42(95.5\%); OR: 0.160; IC95\%: 0.035$0.729 ; \mathrm{p}=0.018]$.

Conclusions: Prison doctors know little about what professional deontology really is. This knowledge increases with age in the profession and is associated with an increased perception of deontological issues in daily practice.
\end{abstract}

Keywords: Ethical Theory; Prisons; Prisoners, Ethics; Codes of ethics; Spain; Medicine; Physicians.

Text received on: 10/12/2014

\section{INTRODUCTION}

Medical deontology includes a series of regulations that physicians use looking for excellence in everyday practice of their profession. Professional associations are corporations governed by public law whose main objective is the organization of the profession, the representation of professionals and the defense of their interests. The State recognizes that professional associations, including medical ones, have a self-regulating power to determine the principles and rules governing their activity. This in included in Act $2 / 1974$ as of December $26^{\text {th }}$, on the rules regulating professional associations, whose non-amended Article 5 establishes their own legal personality and their full regulatory capacity within the scope of their respective competences ${ }^{1}$. Therefore medical deontology establishes the duties that medical professionals demand from themselves in the performance of their
Text accepted on: 01/27/2015

professional activity and is coercive with regard to the fact that its fulfillment can be required by professional associations under the menace of penalty. Such coerciveness was at the time sanctioned by the Constitutional Court ${ }^{2}$ and the obligation to comply with it is also included in Article 4.5 of the more recent Act $44 / 2003$, on the organization of health professions ${ }^{3}$. This is one of the main attributes of professional associations and such duties are included in the Code of Medical Ethics (CMD) ${ }^{4}$ which includes a set of mandatory rules for physicians and which applies to any medical action, in addition to common legal regulations. Moreover, medical deontology guarantees a commitment by physicians beyond the mere fulfillment of the law, a commitment of ethical imperative that common legal regulations cannot and would never intend to achieve ${ }^{5}$. Currently the Congress of Deputies is discussing a draft bill on professional associations, which strengthens the role of such associ- 
ations as far as professions' deontological regulations are concerned even further.

In spite of the coerciveness of medical deontology there is a lack of studies on the knowledge and compliance of physicians on this matter, and those that we have found reveal far from encouraging results ${ }^{6,7}$. The work developed in prisons, including health care provided in such facilities, is submitted to extreme scrutiny, both from an administrative and a judicial point of view. Such control entails that imprisoned individuals far from being "outsiders" lie "at the very heart of law" in the words of M. Focault ${ }^{8}$ and can and must enjoy their full individual rights regardless of the sentence or the law, among which the right to the protection of health plays a key role. The aforementioned control has made physicians developing their tasks in prisons real experts on legal and administrative issues governing the provision of healthcare to individuals deprived from their freedom. Common sense tells us that since medical deontology is binding for any physician as it has been previously stated prison healthcare providers must be familiar with its regulations and must comply with them in their professional exercise. Moreover, the fulfillment of deontological requirements is a guarantee of the independence of professional exercise ${ }^{5}$, which is usually threatened by the multitude of regulations governing everyday life in prisons and the strict hierarchical nature of the correctional system. We have not found any studies on the degree of knowledge and compliance on this matter. Our objective is to find out the level of awareness on professional deontology and the attitude towards it among prison doctors.

\section{MATERIAL AND METHODS}

Design: descriptive cross-sectional multi-center study carried out by means of the completion of a questionnaire sent by email.

Scope: doctors developing their professional exercise in Spanish prisons.

The questionnaire was sent in February 2012 to all detention facilities, questionnaires received within three months were included in the study and throughout March and April reminders were sent as to achieve further answer rates.

Instruments and Procedures: a survey including 29 questions was designed. Only 1 was a numeric question, 26 questions were close-ended and codified with multiple choice answers to enter one or more answers and finally there were 2 open-ended questions to define concepts by means of short texts. Once the questionnaire had been drafted a PDF file was created to facilitate the introduction and sending of data by means of text fields and activation of check boxes among the answers offered. This file was sent by email together with a presentation and instruction letter to all prison doctors. Once the answers were received they were included in a data base for eventual processing.

Variables collected: information on social and demographical matters was collected by variables such as: gender, age or facility where professional activity is performed. Information on educational background and professional activity was also gathered: education and training, employment status, professional experience and experience in detention facilities. Finally, information on attitudes towards and knowledge on ethical deontological and legal matters regarding the exercise of the medical profession was also collected.

Data processing: A data base was created by means of ACCESS-2007, where the answers sent were protectively introduced through previous codification of answer fields as to correct possible mistakes in the introduction of answers. Open-ended answers were also coded according to groups. Once fulfilled data was exported to a data file to be processed by IBM Statistics SPSS v.20 software.

Once exported and prior to any calculation, another data cleansing procedure was completed to control the quality of the data by means of two types of techniques:

\section{LOGIC AND RANK-TESTS}

Obtaining of the distribution of missing values or unknown values by means of the MVA procedure (Missing Value Analysis) implemented by the software.

Statistical analysis: a descriptive analysis of the sample was carried out in the first place. For the only quantitative variable, its median and corresponding interquartile rank were used, since it did not follow a normal distribution after applying the Kolmogorov-Smirnov test. The rest of qualitative variables were expressed as absolute and relative frequencies. To continue, a bivariate analysis was carried out by means of binary logistic regression models, upon determination of the odds ratio with its corresponding $95 \%$ confidence intervals. In this analysis the following dependent variables were randomly established: age (50 or older and younger than 50 ); experience regarding the exercise of medicine and the performance of the profession in prisons ( 15 or more years and less 
than 15 years); population hosted in the detention facility (800 or less or more than 800 ); knowledge on the correct definition of deontology (yes or no) according to the researchers' opinion and knowledge on and implementation of the code of medical ethics (yes or no).

Ethical and administrative aspects: since it was an opinion questionnaire fulfilled by free individuals who required no further intervention its implicit informed consent was implied to participate in the study.

\section{RESULTS}

118 practitioners from 49 different facilities located in 16 autonomous communities answered the questionnaire, which implies that $28.6 \%$ out of the total 412 physicians performing their job within pris-

Table 1: Main features on the sample $(\mathrm{n}=118)$

\begin{tabular}{lc}
\hline Gender & \\
$\quad$ Male & $68(57.6 \%)$ \\
Female & $50(42.2 \%)$ \\
Age & $51(50-53)$ \\
$\quad \leq 50$ & $45(38.1 \%)$ \\
$\quad>50$ & $73(61.9 \%)$ \\
Professional experience & \\
$\quad \leq 15$ years & $11(9.3 \%)$ \\
$>15$ years & $107(90.7 \%)$ \\
Experience in prisons & \\
$\quad \leq 15$ years & $34(37.3 \%)$ \\
$\quad>15$ years & $74(62.7 \%)$ \\
Experience in a facility of & \\
$\quad \leq 800$ inmates & $48(40.7 \%)$ \\
$>800$ inmates & $70(59.3 \%)$ \\
Administrative status & \\
$\quad$ Established official & $92(78 \%)$ \\
$\quad$ Temporary official & $15(12.7 \%)$ \\
Other & $11(9.3 \%)$ \\
Correctly defines what professional deontology is \\
$\quad$ Yes & $49(41.5 \%)$ \\
No & $69(68.5 \%)$ \\
Attitude towards the Code of Medical Ethics & \\
Knows about it and implements it in & $37(31.3 \%)$ \\
everyday practice & \\
$\quad$ Does not know about it and ignores it & \\
in everyday practice & \\
\hline
\end{tabular}

Median (25-75 percentile) on health ${ }^{9}$ took part in the study. $68(57.6 \%)$ were men and the median age was 51 years old (50-53). 107 $(90.7 \%)$ had a professional experience of over 15 years and had been members of the medical association for the same period of time and $74(62.7 \%)$ had an experience of over 15 years in prisons. Other features of the sample are displayed in Table 1.

Professional deontology was correctly defined by 49 physicians ( $41.5 \%$ out of the total sample) and $37(31.3 \%)$ reported knowing and implemented the Code of Medical Ethics. 113 of respondents reported challenges from an ethical or deontological point of view and $99(83.9 \%)$ believed that a prison Care Ethics Committee is necessary. Other answers to ethical-deontological-professional issues are displayed in Table 2. The main ethical or deontological issues reported by respondents are the following: administrative impositions in their professional practice (78); violation of medical secrecy obligations (57); imposition of compulsory treatment (46); relationship issues with other colleagues (38); forced feeding in cases of hunger strike (25) and issues regarding the relationship with the pharmaceutical industry (18).

Bivariate analysis revealed no significant differences with regard to the size of the facility where healthcare is provided. On the other hand there were some differences with regard to the other four categories of analysis. There was less objection among practitioners older than 50 years [ $9(12.3 \%)$ vs. $13(28.9 \%)$. OR: 0,029; 95\%CI: 0.134-0.895; $\mathrm{p}=0.029]$ and established officers were involved in more administrative issues [9(12.3\%) vs. $13(28.9 \%)$. OR: 0.029; $95 \% \mathrm{CI}$ : $0.134-0.895 ; \mathrm{p}=0.029]$ and legal problems $[47(51.4 \%)$ vs. $6(23.1 \%)$. OR: 3.481 ; $95 \%$ CI: 1.281 to $9.461 ; \mathrm{p}=$ 0.014 ] than temporary employees (Table 3 ).

The greatest differences are found with regard to professional experience in prisons. The longer physicians have worked in prisons the more administrative and legal problems they face, as well as having an improved knowledge of the Deontology Commission and its functions and a deeper awareness on deontological issues (see Table 4). However, practitioners with less experience believe more in the need of a prison Care Ethics Committee [42 (95.5\%) vs. 57 (77.0\%). OR: $0.160 ; 95 \%$ CI: 0.035 to $0.729 ; p=0.018$ ] (Table 4). On the other hand, those who correctly define what professional deontology is find more deontological issues in their everyday practice and more actively defend deontological principles sin they are more willing to denounce colleagues violating these principles and they exercise more their right to conscientious objection (see Table 4). 
Table 2: professional ethical and deontological matters

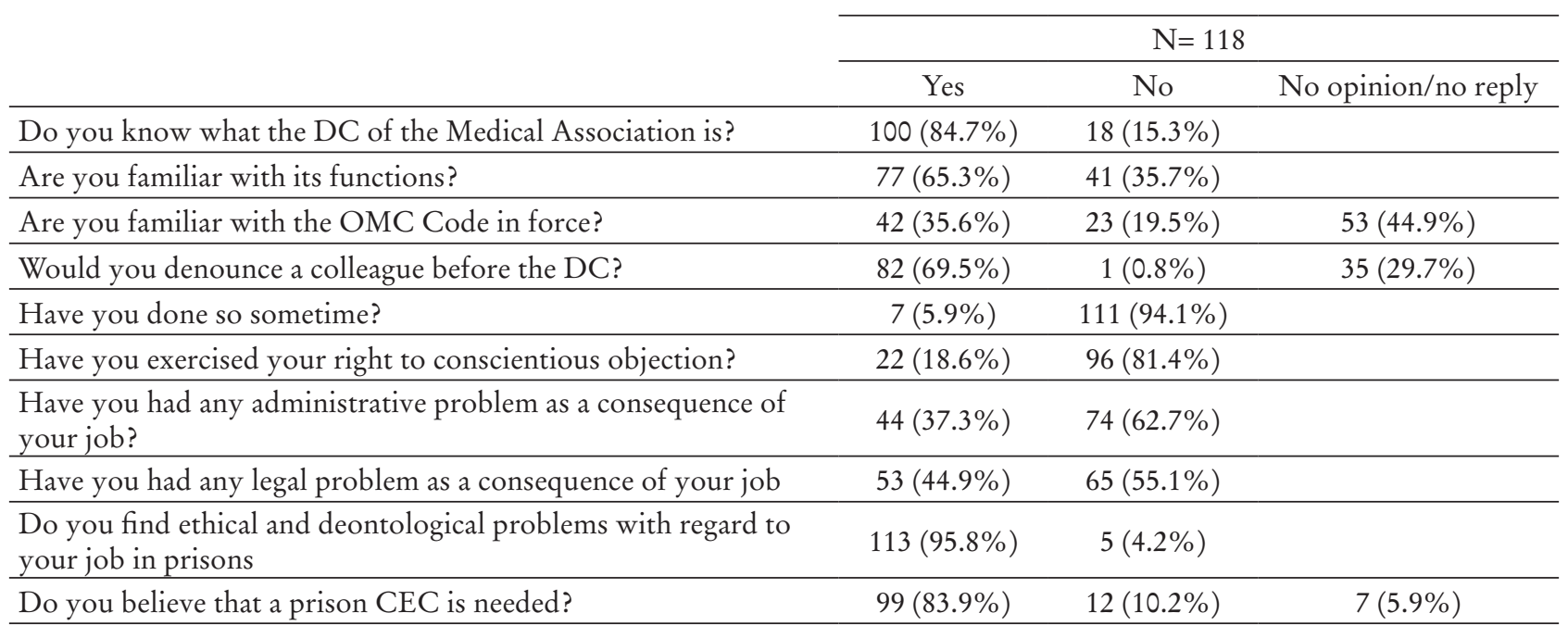

DC: Deontology Commission; OMC: Spanish Medical Colleges Association; CEC: Care Ethics Committee

Table 3. Results of bivariate analysis according to respondent age and employment status (only variables which achieved statistical significance are displayed).

ANALYSIS ACCORDING TO AGE

\begin{tabular}{|c|c|c|c|c|c|c|c|}
\hline \multicolumn{3}{|l|}{ Variable } & $\begin{array}{c}\leq 50 \text { years } \\
(n=45)\end{array}$ & $\begin{array}{c}>50 \text { years } \\
(\mathrm{n}=73)\end{array}$ & $\mathrm{p}$ & OR & $95 \% \mathrm{CI}$ \\
\hline \multirow{2}{*}{\multicolumn{2}{|c|}{ Administrative Issues }} & Yes & $14(31.1 \%)$ & $30(41.1 \%)$ & \multirow{2}{*}{0.277} & \multirow{2}{*}{1.545} & \multirow{2}{*}{$0.705-3.386$} \\
\hline & & No & $31(68.9 \%)$ & $43(58.9 \%)$ & & & \\
\hline \multirow{2}{*}{\multicolumn{2}{|c|}{ Legal Issues }} & Yes & $16(35.6 \%)$ & $37(50.7 \%)$ & \multirow{2}{*}{0.110} & \multirow{2}{*}{1.863} & \multirow{2}{*}{$0.868-3.998$} \\
\hline & & No & $29(64.4 \%)$ & $36(49.3 \%)$ & & & \\
\hline \multirow{2}{*}{\multicolumn{2}{|c|}{ Conscientious objection }} & Yes & $13(28.9 \%)$ & $9(12.3 \%)$ & \multirow{2}{*}{0.029} & \multirow{2}{*}{0.346} & \multirow{2}{*}{$0.134-0.895$} \\
\hline & & No & $32(71.1 \%)$ & $64(87.7 \%)$ & & & \\
\hline \multirow{2}{*}{\multicolumn{2}{|c|}{ Would you denounce a colleague? }} & Yes & $26(57.8 \%)$ & $51(69.9 \%)$ & \multirow{2}{*}{0.182} & \multirow{2}{*}{1.694} & \multirow{2}{*}{$0.781-3.675$} \\
\hline & & No & $19(42.2 \%)$ & $22(30.1 \%)$ & & & \\
\hline \multirow{2}{*}{\multicolumn{2}{|c|}{ Are you familiar with the functions of the DC? }} & Yes & $26(27.8 \%)$ & $51(69.9 \%)$ & \multirow{2}{*}{0.182} & \multirow{2}{*}{1.694} & \multirow{2}{*}{$0.781-3.675$} \\
\hline & & No & $19(42.2 \%)$ & $22(30.1 \%)$ & & & \\
\hline \multicolumn{8}{|c|}{ ANALYSIS ACCORDING TO EMPLOYMENT STATUS } \\
\hline \multicolumn{2}{|l|}{ Variable } & \multicolumn{2}{|c|}{$\begin{array}{c}\text { Other situation } \\
(\mathrm{n}=26)\end{array}$} & $\begin{array}{c}\text { Established } \\
\text { officer }(n=92)\end{array}$ & $\mathrm{p}$ & OR & $95 \% \mathrm{CI}$ \\
\hline \multirow{2}{*}{ Administrative Issues } & Yes & \multicolumn{2}{|c|}{$45(15.4 \%)$} & $40(43.5 \%)$ & \multirow{2}{*}{0.013} & \multirow{2}{*}{4.231} & \multirow{2}{*}{$1.350-13.26$} \\
\hline & No & & $34.6 \%)$ & $52(56.5 \%)$ & & & \\
\hline \multirow{2}{*}{ Legal Issues } & Yes & & $3.1 \%)$ & $47(51.4 \%)$ & \multirow{2}{*}{0.014} & \multirow{2}{*}{3.481} & \multirow{2}{*}{$1.281-9.461$} \\
\hline & No & & $76.9 \%)$ & $45(48.9 \%)$ & & & \\
\hline \multirow{2}{*}{ Would you denounce a colleague? } & Yes & & $34.6 \%)$ & $60(65.2 \%)$ & \multirow{2}{*}{0.066} & 341 & $108-1075$ \\
\hline & No & & $5.4 \%)$ & $32(34.8 \%)$ & & 0.341 & $0.108-1.0 / 5$ \\
\hline oul ever done so? & Yes & & $5.4 \%)$ & $28(30.4 \%)$ & $36+2>3>0$ & 6 & $631+3$ \\
\hline Have you ever done so? & No & & $34.6 \%)$ & $64(69.6 \%)$ & 0.156 & 2.400 & $0.759-7.651$ \\
\hline
\end{tabular}


Table 4. Results of bivariate analysis according to professional experience in prisons and appropriate definition of professional deontology (only variables which achieved statistical significance are displayed).

ANALYSIS ACCORDING TO PROFESSIONAL EXPERIENCE IN PRISONS

\begin{tabular}{|c|c|c|c|c|c|c|}
\hline Variable & & $\begin{array}{c}\leq 15 \text { years } \\
(n=44)\end{array}$ & $>15$ years $(n=74)$ & $\mathrm{p}$ & OR & $95 \% \mathrm{CI}$ \\
\hline \multirow{2}{*}{ Administrative Issues } & Yes & $7(15.9 \%)$ & $37(50.0 \%)$ & \multirow{2}{*}{0.0001} & \multirow{2}{*}{5.286} & \multirow{2}{*}{$\begin{array}{l}2.091- \\
13.363\end{array}$} \\
\hline & No & $37(84.1 \%)$ & $37(50.0 \%)$ & & & \\
\hline \multirow{2}{*}{ Legal Issues } & Yes & $10(22.7 \%)$ & $43(58.1 \%)$ & \multirow{2}{*}{0.0001} & \multirow{2}{*}{4.716} & \multirow{2}{*}{$\begin{array}{l}2.030 \\
10.955\end{array}$} \\
\hline & No & $34(77.3 \%)$ & $31(41.9 \%)$ & & & \\
\hline \multirow{2}{*}{ Is a prison CEC necessary? } & Yes & $42(95.5 \%)$ & $57(77.0 \%)$ & \multirow{2}{*}{0.018} & \multirow{2}{*}{0.160} & \multirow{2}{*}{$0.035-0.729$} \\
\hline & No & $2(4.5 \%)$ & $17(23.0 \%)$ & & & \\
\hline \multirow{2}{*}{ Have you denounced a colleague? } & Yes & $5(11.4 \%)$ & $27(36.5 \%)$ & \multirow{2}{*}{0.005} & \multirow{2}{*}{4.481} & \multirow{2}{*}{$\begin{array}{l}1.577- \\
12.733\end{array}$} \\
\hline & No & $39(88.6 \%)$ & $47(63.5 \%)$ & & & \\
\hline \multirow{2}{*}{$\begin{array}{l}\text { Are you familiar with the functions of } \\
\text { the DC? }\end{array}$} & Yes & $23(52.3 \%)$ & $54(73.0 \%)$ & \multirow{2}{*}{0.024} & \multirow{2}{*}{2.465} & \multirow{2}{*}{$1.127-5.394$} \\
\hline & No & $21(47.7 \%)$ & $20(27.0 \%)$ & & & \\
\hline
\end{tabular}

CEC: Care Ethics Committee; DC: Deontology Commission

ANALYSIS ACCORDING TO CORRECT DEFINITION OF PROFESSIONAL DEONTOLOGY

\begin{tabular}{|c|c|c|c|c|c|c|}
\hline Variable & & Incorrect $(n=69)$ & Correct $(n=49)$ & $\mathrm{p}$ & OR & $95 \% \mathrm{CI}$ \\
\hline \multirow{2}{*}{$\begin{array}{l}\text { Do you find deontological issues in } \\
\text { your everyday practice? }\end{array}$} & Yes & $18(26.1 \%)$ & $23(46.9 \%)$ & \multirow{2}{*}{0.020} & \multirow{2}{*}{2.506} & \multirow{2}{*}{$1.153-5.451$} \\
\hline & No & $51(73.9 \%)$ & $26(53.1 \%)$ & & & \\
\hline \multirow{2}{*}{ Would you denounce a colleague? } & Yes & $42(60.9 \%)$ & $40(81.6 \%)$ & \multirow{2}{*}{0.018} & \multirow{2}{*}{2.857} & \multirow{2}{*}{ 1.197-6.819 } \\
\hline & No & $27(39.1 \%)$ & $9(18.4 \%)$ & & & \\
\hline \multirow{2}{*}{ Conscientious objection } & Yes & $9(13.0 \%)$ & $13(26.5 \%)$ & \multirow{2}{*}{0.068} & \multirow{2}{*}{2.407} & \multirow{2}{*}{$0.936-6.194$} \\
\hline & No & $60(87.0 \%)$ & $36(73.5 \%)$ & & & \\
\hline
\end{tabular}

\section{DISCUSSION}

We have assessed the knowledge on and the attitude towards medical deontology among a very specific group of physicians such as those performing their tasks within the Prison Health system. The importance of deontological values and principles has become greater than ever since at the expense of scientific progress, individual dignity may be jeopardized. Not everything that can be scientifically done is acceptable from an ethical or deontological point of view. With reference to prisons, Deontology -what should be done from a professional point of viewshould become even more important, due to the extreme regulation involving all the activities performed there. There are two key aspects which may directly influence the relationship between doctors and patients in prisons. On the one hand there is a two-fold asymmetric relationship since along with the traditional unbalance implied by the fact that physicians act from a superior position due to their technical knowledge, they are also members of the prison staff - something with may entail an undesirable hierarchical relationship which may challenge the necessary confidence which should govern relations between a doctor and his/her patients. On the other hand, we find the duties of physicians as members of such staff, which may entail a series of obligations which can be hardly compatible with those owed to the patients. This is the so called two-fold fidelity conflict and it can imply deontological conflict with regard to the respect for patients' decisions or the protection of medical secrecy. These situations are included in the Code of Medical Ethics ${ }^{4}$ and they should be known and complied with by all Spanish physicians, including those developing their practice in prisons.

Yet our results do not seem to be in line with this thesis since both the definition of medical deontology and the degree of knowledge on the CME is lower than in other groups ${ }^{6-7}$. One of the plausible explanations for this is the extreme judicial regulation of health care provided in prisons which may entail an urge for security and awareness of legal rules and a conception of deontology as a subjective matter typical of pro-corporate obsolete professional associations, alien to today's moral diversity and thus dispensable. We should take into account that while it would be possible to practice good medicine without laws 
it would be completely impossible to do so without ethical and deontological regulations. Doctors, by the mere fact of being so and exercising the profession, are committed to loyalty towards their patients, to a generous sincere interest to make things as well as possible and to an ethical exigency beyond the mere Law, embodied in the CME.

However there are some aspects of our results which highlight the influence of the regulating and legalistic background of prison health care. Prison doctors practically unanimously report the existence of ethical issues in their everyday practice and to a much higher extent than other jobs, entailing deontological aspects with regard to the provision of care in prisons which are conditioned by the specific background, as it had been previously stated. From this point of view, the practice of Medicine is somewhat "particular" since the three more common ethical issues reported by doctors (administrative imposition, violation of medical secrecy and forced treatment) are practically not mentioned in the rest of the studies ${ }^{6-7}$. On the other hand, there is more prison doctors involved in legal issues than physicians performing their job in other settings, a fact in line with the aforementioned excessively legalistic background.

We have also found personal factors modifying the opinion on this issue among prison doctors. At large among prison doctors, the older they are and the more established their employment status is, the more administrative and legal issues they become involved with. This can be due to the passage of time but also because employment stability entails further personal safety to face those issues. Furthermore, over time professionals become more aware of medical deontology, they identify more deontological issues in their everyday practice and they are stricter with colleagues breaching its rules. This can be interpreted as awareness on the fact that the law itself is not enough, for the practice of medicine further ethical exigencies are needed, and this should be defined by an agreement on self-regulation among physicians, represented by the CME. This is even more so in prison medical practice due to its particularities.

We have to point out two limitations of the study. First, with regard to the representativeness of the sample, especially due to the means of getting it since there was not a random selection of respondents and therefore bias cannot be ruled out. The other issue involves the validation of the survey a complex difficult matter which implies a pilot survey. The questionnaire sent to prison doctors included that feature but we finally discarded it due to the number of answers achieved and the limited total number targeted, which would probably entail disadvantageous further efforts in this sense. Regardless of these limitations, it is worth noting that this is the first study on this issue among prison doctors and one of the few among physicians and it can represent a strong basis upon which building further studies.

\section{CORRESPONDENCE}

Julio García-Guerrero

Medical Services

Prison of Castellon I

Ctra. de Alcora, km 10. 12006 Castellón de la Plana.

email: garciaj@comcas.es

\section{BIBLIOGRAPHIC REFERENCES}

1. Act $2 / 1974$, as of February 13th, on Professional Associations. Official State Gazette number 40, February 15th 1974: 3046-9.

2. Ruling of the Constitutional Court 219/1989, as of December 21st 1989. Official State Gazette number 10, January 11th 1990: 73-6.

3. Act $44 / 2003$, as of November 21 st on the organization of health professions. Official State Gazette number 280, November 22nd 2003: 41442-58.

4. Spanish Organization of Medical Associations. Code of Medical Ethics. Guidelines on medical ethics [Internet]. Madrid: General Council of Official Medical Associations; 2011. [cited 2014 Sept 15]. Available from: http://www.cgcom.es/ sites/default/files/codigo_deontologia_medica.pdf

5. Altisent R. Etica, bioetica y deontologia. Rev Bioet 2009; 17(3): 363-75.

6. Collazo Chao E. Proposal for the updating of the Code of Medical Ethics of the Spanish Organization of Medical Associations [Doctoral thesis]. Cordoba: University of Cordoba;2009.

7. López-Marín S. Medical Ethics and Deontology. Ethics of Primary Care in Toledo [Doctoral thesis]. Salamanca: University of Salamanca; 2009.

8. Foucault M. Discipline and punish: The birth of the prison. Madrid: Editorial Siglo XXI; 2008: 307.

9. General Secretariat of Penitentiary Institutions. 2012 General Report [Internet]. Madrid: Ministry of the Interior, Technical General Secretary; 2013. [cited 2012 Dec 09]. Available from: http:// www.institucionpenitenciaria.es/web/export/ sites/default/datos/descargables/publicaciones/ Informe_General_2012_acc_Web.pdf 